\title{
Association of Severity of Coronary Lesion with Markers of Acute Infection and Inflammation in Patients with Acute Coronary Syndrome
}

\author{
Sedat Koçak ${ }^{1}$, Atıf Harmankaya ${ }^{2}$, Esma Erdemir ${ }^{3}$, Zerrin Defne Dündar ${ }^{1}$, Recep Keşli ${ }^{4}$, Hayrudin Alibasic ${ }^{5}$ \\ 'Department of Emergency, Necmettin Erbakan University Meram School of Medicine, Konya, Turkey \\ ${ }^{2}$ Clinic of Emergency, Yunus Emre State Hospital, Eskişehir, Turkey \\ ${ }^{3}$ Clinic of Emergency, Beyhekim State Hospital, Konya, Turkey \\ ${ }^{4}$ Department of Microbiology, Kocatepe University School of Medicine, Afyon, Turkey \\ ${ }^{5}$ Clinic of Cardiology, Özel Büyükşehir Hospital, Konya, Turkey
}

\begin{abstract}
Aim: Inflammation and some infectious agents play a key role in acute coronary syndrome (ACS) caused by atherosclerosis. The purpose of this study was to assess the effects of inflammatory markers and the positivity of Chlamydia pneumoniae (CP), Helicobacter pylori (HP), and Cytomegalovirus (CMV) on the level of atherosclerosis in patients with ACS.
\end{abstract}

Materials and Methods: Patients (57) that were referred to the emergency unit with classic angina symptoms or angina equivalent symptoms and were determined to have critical lesions in the coronary angiography (>70\% stenosis, coronary artery disease (CAD) severity assessed by the Gensini score) were compared with 27 ACS patients who had no critical lesions in terms of procalcitonin (PCT), tumor necrosis factor-alpha (TNF-a), interleukin-2 receptor (IL2r), interleukin-6 (IL-6), and interleukin-10 (IL-10) levels and positivity of CP, HP, and CMV. Also, the two groups of ACS patients were compared in terms of cytokine levels measured at hours 0 and 48.

Results: No significant association was found between the degree of the coronary lesion and the inflammatory and infectious agents. However, in patients with critical coronary lesions, as markers of inflammatory agents, the levels of IL- 6 were significantly lower and levels of IL-10 were significantly higher ( $p<0.001$ and $p=0.030$, respectively) at hour 48 than originally found at hour 0 .

Conclusion: There is no association between the severity of coronary lesions and cytokine levels and positivity of infectious agents in ACS since the levels of proinflammatory cytokines in ACS are higher than those in atherosclerosis. The changes in cytokine levels at hour 48 were found to be significant.

Keywords: Coronary lesion, biomarkers, infection, inflammation, acute coronary syndrome

\section{Introduction}

Inflammation plays a key role in atherosclerosis, which leads to acute coronary syndrome (ACS) (1-3). The pro-inflammatory markers interleukin-6 (IL-6) and tumor necrosis factor-alpha (TNF-a) along with anti-inflammatory marker interleukin-10 (IL-10) are described as part of the inflammatory process in atherosclerosis (4). IL-2 and interleukin-2 receptor (IL-2R), which is expressed on the surface of lymphocytes, have key roles in the beginning of inflammation via their direct effects on T cells (5). Various studies have shown that the diffuseness of atherosclerosis and then the probability of coronary artery disease (CAD) can be predicted by studying the levels of inflammatory markers in healthy individuals $(6,7)$.

A series of studies have reported that infectious agents of low virulence, such as Chlamydia pneumoniae (CP), Helicobacter pylori (HP), and Cytomegalovirus (CMV), may play a role in the pathogenesis of atherosclerosis by affecting the coronary artery walls. These studies have claimed that these agents may directly induce inflammation in the arterial walls by mechanisms such as innate immunity, molecular imitation, and autoimmunity (8-11).

The purpose of this prospective study was to assess the association of inflammatory markers and the positivity of CP, HP, and CMV with the severity of atherosclerosis in patients with ACS.

The study was presented partially on $1^{\text {st }}$ International Emergency Medicine Symposium, 13-15 April 2012, Baku, Azerbaijan.

Correspondence to: Sedat Koçak e-mail: skocak@konya.edu.tr

Received: 21.06.2016 Accepted: 06.12.2016

(C) Copyright 2016 by Emergency Physicians Association of Turkey - Available online at www.eajem.com

DOI: 10.5152/eajem.2016.79188 


\section{Materials and Methods}

\section{Study population}

The study included patients referring with angina symptoms and angina equivalent symptoms to the emergency department of a university hospital in the 6 month period between July 2011 and January 2012. The patients who had clinical, electrocardiographic (ECG) (concordant ST elevation $>1 \mathrm{~mm}$ in leads with a positive QRS complex, concordant ST depression $>1 \mathrm{~mm}$ in V1-V3, excessively discordant ST elevation $>5 \mathrm{~mm}$ in leads with a negative QRS complex; Sgarbossa criteria), and echocardiographic (ECHO) findings (wall motion disorder), changes in cardiac markers, and critical lesions determined by coronary angiography comprised the test group; and patients with no critical lesions found in coronary angiography comprised the control group.

\section{Exclusion criteria}

The cases with the following disorders, which might affect the obtained data (related to the infection and inflammation process), were excluded from the study: chronic renal insufficiency, hepatic insufficiency, advanced cardiac failure, respiratory insufficiency, rheumatic disease, sepsis, and cancer or undergoing cancer therapy.

\section{Study protocol}

The following features of the patients were noted: age, sex, pulse rate, respiratory rate, average blood pressure, body temperature, history of alcohol consumption and smoking, hyperlipidemia $(\mathrm{HL})$, diabetes mellitus (DM), hypertension (HT); presence of CAD, cerebrovascular event (CVE) or coronary artery bypass graft operation (CABGO) surgery in the anamnesis; and presence of unstable angina pectoris (USAP) or acute myocardial infarction (AMI) at the time of referral. At the time of patients' referral to the emergency unit, the following were tested and their levels were noted: white blood cells (WBC), creatine-kinase-MB fraction (CK-MB), troponin-I (Tnl), procalcitonin (PCT), TNF-a, IL-2R, IL-6, IL-10, triglyceride (TG), cholesterol, low density lipoprotein (LDL), high density lipoprotein (HDL), international normalized ratio (INR), activated partial thromboplastin time (aPTT), CMV, HP, and CP. Likewise, after 48 hours, the following were tested and their levels were noted: WBC, CK-MB, troponin-I, TNF-a, IL-2R, IL-6, and IL-10.

The criteria for HT was a blood pressure over 140/90 $\mathrm{mm} \mathrm{Hg}$ after resting for at least 10 minutes or the presence of HT or history of antihypertensive agent use; for DM, fasting blood glucose level over 126 $\mathrm{mg} / \mathrm{dL}$ or use of antidiabetic agents; and for $\mathrm{HL}$, lipoprotein level over $130 \mathrm{mg} / \mathrm{dL}$ or TG level over $200 \mathrm{mg} / \mathrm{dL}$ or use of hypolipidemic agents.

Venous blood specimens of $10 \mathrm{cc}$ were taken from each patient at the time of referral and also after 48 hours. Complete blood count and cardiac marker tests were performed immediately after samples were taken; blood specimens to be tested for inflammatory markers were centrifuged and then kept at $-80^{\circ} \mathrm{C}$ until the time of testing. All patients included in the study were informed about the investigation, and their consents were obtained. The study was begun after obtaining approval from the local ethics committee of Meram Medical Faculty (approval date and no: 24.02.2011 - 056).

\section{Angiographic assessment of coronary artery disease severity}

The anatomic severity was determined with a high-quality cineangiogram. The severity of the lesions in the arteries was measured and noted. A critical lesion was defined as $70 \%$ stenosis in at least one artery. The number of lesions and severity and anatomic localization of the obstruction were assessed by the Gensini score (12). The angiographic examinations of the patients were performed by cardiologists who did not take part in the study.

\section{Markers of inflammation}

The inflammatory and cytokine profiles of the patients were determined by laboratory staff who did not know of the patients' angiograms. The presence of CMV-DNA (Artus ${ }^{\mathrm{TM}}, \mathrm{GmbH}$, Hamburg, Germany), HP-DNA (Artus ${ }^{\mathrm{TM}}, \mathrm{GmbH}$, Hamburg, Germany), and CP-DNA (Artus $^{\mathrm{TM}}, \mathrm{GmbH}$, Hamburg, Germany) in the sera of both the test and control patients were assessed using the real-time polymerase chain reaction $(P C R)$ method. The DNA material in the sera was extracted with an automated DNA extraction device (EZ1 Advanced- $\mathrm{XL}^{\mathrm{TM}}{ }^{\mathrm{M}}$ Qiagen Instruments, Hombrechitkon, Switzerland) using DNA extraction kits for C. pneumoniae and H. pylori (EZ1 ${ }^{\mathrm{TM}}$ Bacteria Mini Kit V2.0, Qiagen GmbH, Hilden, Germany) and for CMV (EZ1 ${ }^{\mathrm{TM}}$ Virus Mini Kit V2.0, Qiagen GmbH, Hilden, Germany). The DNAs were determined with real-time PCR using a Rotor-Gene $\mathrm{Q}^{\mathrm{TM}}$ cycler (Qiagen, Hilden, Germany).

The assays for IL-2, IL-6, IL-10, and TNF-a (Seimens Healthcare Diagnostics Products Ltd., Lianberis, Gwynedd, UK) levels were carried out with the chemiluminescence method (Immulite $1000^{\text {TM }}$ Immunoassay System, Siemens Healthcare Diagnostics Ltd., NJ, USA). The procalcitonin assays (Procalcitonin, Siemens Healthcare Diagnostics Inc., Tarrytown, NY, USA) were also performed with the chemiluminescence method (AdviaCentaur XP ${ }^{\mathrm{TM}}$ immunoassay System, Siemens Healthcare Diagnostics Inc., Tarrytown, NY, USA).

\section{Statistical analysis}

For statistical analysis, the Statistical Package for the Social Sciences $^{\mathrm{TM}}$ version 15.0 (SPSS Inc.; Chicago, IL, USA) software package was used. The quantitative variables were expressed as mean \pm standard deviation and categoric variables as number of cases (\%). All data were subjected to normality analysis. For the comparison of the test group with the control group, quantitative variables with normal distribution were compared with a Student's t-test and quantitative variables with non-normal distribution with a Mann-Whitney $U$ test. The categoric variables of the two groups were compared with the chi-square test and Fisher's exact test. The patients' variables dependent on the change of markers with time were evaluated with t-tests (paired samples t-test).

\section{Results}

The study included 57 test and 27 control patients, a total of 84 patients. Of the test and control patients, 46 (80.7\%) and 11 (40.7\%) were males, respectively. Male patients were significantly higher in the test group $(p=0.006)$. The respective mean ages of the test and control groups were $64.67 \pm 11.63$ and $61.04 \pm 13.44$ and there was no significant difference $(p=0.208)$. The demographic data of the test and control groups and the vital findings determined on referral are shown in Table 1. The rates of the presence of $\mathrm{DM}$ and $\mathrm{HL}$ and past CABGO were significantly higher in the test group than in the control group ( $p=0.012, p=0.006$, and $p=0.020$, respectively).

The diagnostic distribution of all patients included in the study is shown in Table 2. The angiographic examination of the 84 patients showed the presence of stenosis varying between $20 \%$ and $70 \%$ in 
Table 1. Demographic data and vital findings were compared in the test and control groups

\begin{tabular}{|c|c|c|c|}
\hline & Control (n:27) & Test (n:57) & $\mathbf{p}$ \\
\hline Age (y) & $61.04 \pm 13.44$ & $64.67 \pm 11.63$ & 0.208 \\
\hline Sex M/F (n) & $14 / 13$ & $46 / 11$ & $0.006^{*}$ \\
\hline \multicolumn{4}{|l|}{ Demographic Data } \\
\hline CAD (\%) & 25.9 & 35.1 & 0.401 \\
\hline DM (\%) & 3.7 & 31.6 & $0.012^{*}$ \\
\hline HT (\%) & 40.7 & 59.6 & 0.105 \\
\hline HL (\%) & 3.7 & 29.8 & $0.006^{*}$ \\
\hline Smoke (\%) & 40.7 & 43.9 & 0.787 \\
\hline Alcohol (\%) & 0 & 1.8 & 0.489 \\
\hline Surgery (\%) & 0 & 17.5 & $0.020 *$ \\
\hline CVE (\%) & 0 & 5.3 & 0.225 \\
\hline $\mathrm{mAP}(\mathrm{mm} / \mathrm{Hg})$ & $84.93 \pm 11.56$ & $96.30 \pm 18.36$ & $0.040^{*}$ \\
\hline Pulse (beats/min) & $77.93 \pm 17.37$ & $80.09 \pm 19.58$ & 0.626 \\
\hline Fever $\left(C^{\circ}\right)$ & $36.70 \pm 0.24$ & $36.62 \pm 0.17$ & 0.828 \\
\hline $\begin{array}{l}\text { Respiratory rate } \\
\text { (respiratory/min) }\end{array}$ & $14.19 \pm 1.38$ & $15.44 \pm 3.95$ & 0.114 \\
\hline \multicolumn{4}{|c|}{$\begin{array}{l}\text { CAD: coronary artery disease; DM: diabetes mellitus; } \mathrm{HT} \text { : hypertension; } \mathrm{HL} \text { : hyperlipi- } \\
\text { demia, CVE: cerebrovascular event, mAP: mean arterial pressure } \\
{ }^{*} \mathrm{p}<0.05\end{array}$} \\
\hline
\end{tabular}

Table 2. Diagnostic distribution of the test and control groups, and coronary lesion severity distribution according to the coronary angiographic evaluation

\begin{tabular}{|l|c|}
\hline \multicolumn{2}{|l|}{ n:84 } \\
\hline Diagnosis \\
\hline -USAP (control) & 27 \\
\hline -USAP (test group) & 6 \\
\hline -NSTEMI & 16 \\
\hline -STEMI & 35 \\
\hline Vessel Lesions < \% 70 & 27 \\
\hline Vessel Lesions > \% 70 & 25 \\
\hline -single vessel & 17 \\
\hline -two vessels & 15 \\
\hline -three vessels & \\
\hline $\begin{array}{l}\text { USAP: unstable angina pectoris; NSTEMl: non ST elevation myocard infarction; STEMI: } \\
\text { ST elevation myocard infarction }\end{array}$ \\
\hline
\end{tabular}

the 27 cases that were not accepted as critical. The distribution of artery pathologies in the 57 patients that were found to have critical lesions in the angiography is also shown in Table 2.

The results of the biochemical and inflammatory markers of the test and control groups measured at the time of referral to the emergency department are shown in Table 3. The CK-MB and Tn-I levels were statistically higher in the test group than those in the control group ( $p<0.001$ and $p=0.001$, respectively). There was no significant
Table 3. Markers of cardiac, inflammatory, and infection were compared in the test and control groups

\begin{tabular}{|c|c|c|c|c|}
\hline & $\begin{array}{c}\text { Reference } \\
\text { Values }\end{array}$ & $\begin{array}{c}\text { Control } \\
\text { (n:27) }\end{array}$ & $\begin{array}{c}\text { Test } \\
\text { (n:57) }\end{array}$ & $\mathbf{p}$ \\
\hline WBC $\left(\times 10^{9} / L\right)$ & & $8.15 \pm 2.78$ & $12.79 \pm 12.28$ & 0.067 \\
\hline CK-MB (ng/mL) & $<5.5$ & $2.00 \pm 1.52$ & $52.20 \pm 88.25$ & $<0.001^{*}$ \\
\hline $\mathrm{Tn}-\mathrm{I}(\mathrm{ng} / \mathrm{mL})$ & $<0.04$ & $0.04 \pm 0.05$ & $13.27 \pm 27.34$ & $0.001^{*}$ \\
\hline $\mathrm{PCT}(\mathrm{ng} / \mathrm{mL})$ & $<0.1$ & $0.10 \pm 0.09$ & $0.10 \pm 0.10$ & 0.974 \\
\hline TNF-a (pg/mL) & $<8.1$ & $1.92 \pm 9.13$ & $3.23 \pm 9.98$ & 0.676 \\
\hline IL-2r (IU/mL) & $158-623$ & $919 \pm 1711$ & $704 \pm 549$ & 0.523 \\
\hline IL-6 (pg/mL) & $3.4-5.9$ & $9117 \pm 16707$ & $12847 \pm 18514$ & 0.409 \\
\hline IL-10 (pg/mL) & $1.5-9.1$ & $61.08 \pm 154.45$ & $25.59 \pm 7.66$ & 0.239 \\
\hline TG (nmol/L) & $35-160$ & $185.88 \pm 160.92$ & $161.60 \pm 138.32$ & 0.490 \\
\hline Cholesterol (nmol/L) & $140-200$ & $183.88 \pm 52.41$ & $177.98 \pm 47.10$ & 0.617 \\
\hline LDL (nmol/L) & $60-130$ & $111.84 \pm 33.85$ & $109.14 \pm 34.09$ & 0.743 \\
\hline HDL (nmol/L) & $30-80$ & $35.84 \pm 12.20$ & $35.57 \pm 9.12$ & 0.913 \\
\hline INR & $0.8-1.2$ & $1.09 \pm 0.08$ & $1.15 \pm 0.23$ & 0.466 \\
\hline APTT (s) & $23-35$ & $25.48 \pm 4.51$ & $29.47 \pm 5.98$ & 0.138 \\
\hline CMV (\%) & & 7.4 & 8.7 & 0.530 \\
\hline HP (\%) & & 11.1 & 10.5 & 0.642 \\
\hline CP (\%) & & 3.7 & 3.5 & 0.704 \\
\hline \multicolumn{5}{|c|}{$\begin{array}{l}\text { WBC: white blood cell; CK-MB: creatine-kinase-MB fraction; Tnl: troponin I; PCT: procalci- } \\
\text { tonin;TNF-a: Tumor necrosis factor-a; IL-2r: interleukin-2 receptor; IL-6: interleukin-6; IL-10: } \\
\text { interleukin-10; TG: triglyceride; LDL: low density lipoprotein; HDL: high density lipoprotein; } \\
\text { INR: international normalized ratio; APTT: activated partial thromboplastin time; CMV: cyto- } \\
\text { megalovirus; HP: helicobacter pylori; CP: chlamydia pneumoniae } \\
\text { *p<0.05 }\end{array}$} \\
\hline
\end{tabular}

Table 4. Comparison of inflammatory and cardiac markers of the patient group on referral to the emergency department and after 48 hours

\begin{tabular}{|l|c|c|c|}
\hline & $\begin{array}{c}\text { initial } \\
\text { values }\end{array}$ & $\begin{array}{c}\mathbf{4 8} \text { hours } \\
\text { later values }\end{array}$ & p \\
\hline IL-6 $(\mathrm{pg} / \mathrm{mL})$ & $12847 \pm 18514$ & $61 \pm 198$ & $<0.001^{*}$ \\
\hline TNF-a $(\mathrm{pg} / \mathrm{mL})$ & $3.23 \pm 9.98$ & $4.29 \pm 13.88$ & 0.667 \\
\hline IL-2r $(\mathrm{IU} / \mathrm{mL})$ & $704 \pm 549$ & $792 \pm 704$ & 0.361 \\
\hline IL-10 $(\mathrm{pg} / \mathrm{mL})$ & $25.59 \pm 7.66$ & $32.72 \pm 15.02$ & $0.030^{*}$ \\
\hline WBC $\left(\times 10^{9} / \mathrm{L}\right)$ & $12.79 \pm 12.28$ & $11.9 \pm 3.63$ & 0.740 \\
\hline CK-MB $(\mathrm{ng} / \mathrm{mL})$ & $52.20 \pm 88.25$ & $14.17 \pm 16.19$ & $0.041^{*}$ \\
\hline Tn-I (ng/mL) & $13.27 \pm 27.34$ & $21.31 \pm 22.41$ & $0.047^{*}$ \\
\hline $\begin{array}{l}\text { IL-6: interleukin-6; TNF-a: tumor necrosis factor-a; IL-2r: interleukin-2 receptor; } \\
\text { IL-10: interleukin-10; WBC: white blood cell; CK-MB: creatine-kinase-MB fraction; Tnl: } \\
\text { troponin I } \\
\text { *p<0.05 }\end{array}$ & & \\
\hline
\end{tabular}

difference between the test group and control group in terms of WBC and PCT values and lipid profile.

When the two groups were compared, no statistically significant correlation was found between the levels of inflammatory markers IL-6, TNF- $\alpha$ and IL-2R and the level of anti-inflammatory marker IL-10. 
Also, there was no statistically significant difference between the two groups in terms of serological positivity of CMV, HP, and CP.

Comparison of inflammatory and cardiac markers of the patient group on referral to the emergency department and 48 hours later are shown in Table 4. In the patient group, the IL- 6 levels measured at hour 48 were statistically lower than those measured at the time of referral, whereas the levels of IL-10 were found statistically higher $(p<0.001$ and $p=0.030$, respectively). There was no statistically significant change in the levels of IL-2R and TNF- $\alpha$ in terms of initial and hour 48 measurements.

\section{Discussion}

It has been shown that various inflammatory markers used to determine cardiovascular risk are useful in the classification of risks, and can also be used in the determination of patients to benefit from interventional therapy (13). Moreover, it has been found that the significant rise in the levels of inflammatory markers in ACS helps in prediction of future cardiovascular risk (14). For instance, it has been claimed that monocyte procoagulant activity stimulated by IL- 6 can cause an association between inflammation and thrombosis in patients with CAD (15). But in our study, we did not find such an association when we assessed the infection seropositivity and acute inflammatory response in the acute stages in patients referring with suspected ACS. Also, we found no significant difference between patients with critical artery lesions and patients with no critical artery lesions in terms of inflammatory cytokine levels (IL-2R, IL-6, IL-10, and TNF-a).

Sukhija et al. (16), in their study of 249 ACS patients referring with chest pain and undergoing angiography, found no significant differences between the levels of IL- 6 and TNF- $a$ and the severity of atherosclerosis.

Gotsman et al. (4), in their study of 119 patients undergoing angiography in a consecutive order, determined a significant association between the markers IL- 6 and TNF- $a$ and the severity of CAD. They observed that, with increasing severity of the arterial lesion, the levels of IL- 6 and TNF-a show a significant rise. The authors determined a strong association between high cytokine levels and the degree of atherosclerosis in the subgroup of patients with a stabile coronary; but in the ACS subgroup, a weak association between TNF-a and atherosclerosis was found with no association between IL- 6 and atherosclerosis. This situation is caused by the rise in proinflammatory cytokine levels during acute coronary events, which leads to the rise in cytokine levels; and for this reason, an association between cytokine levels and severity of CAD cannot be established (4).

Heinisch et al. (17) compared 20 ACS patients (AMI and USAP) with 20 stabile angina pectoris (SAP) patients in terms of IL-6 and TNF- $a$ levels and determined a significant rise in IL- 6 and TNF- $a$ levels in the ACS group. Although they observed the IL- 6 levels in ACS patients to be indeterminable after 15 to 30 days, they found a significant rise in the TNF-a levels of ACS patients after 30 days (17). When this situation was interpreted in light of former studies (7), it was claimed that TNF-a levels rise in the months following AMI and this rise increases the risk of coronary event recurrances (17).

In their study, Sakamoto et al. (18) divided 286 patients angiographically assessed into two groups based on arterial lesions as the CAD group and a healthy control group. They found significantly higher levels of IL-2R in the CAD group than in the control group. Nijm et al. (19) compared a total of 65 CAD patients, which included
20 patients diagnosed with ACS upon their referral and 45 patients of SAP determined to have significant stenosis in the angiography performed at the time of referral, with 45 healthy controls in terms of IL-2R and IL-10 levels and found no significant difference between the two groups. Hu and Hwang (20), in their study of AMI, USAP, SAP, and control groups (20 subjects in each), found significantly high levels of IL- 6 and IL-10 only in the AMI group when compared with the control group. They determined no significant difference in TNF-a levels between AMI, USAP, and SAP groups, but significant levels of TNF-a in all these groups when compared with the control group. After one week, they found a significant decrease in IL-6 levels in the AMI group, but no changes in the levels of IL-10 and TNF- $a$ (20). In our study, after 48 hours, we found a statistically significant decrease in IL- 6 and significant increase IL-10 levels, but an insignificant increase in TNF-a level. In the literature, heterogeneity among the compared groups, the difference in test repetition times, small study populations, the fact that they are single-centered studies, and inconsistency between the results obtained are insufficient to make concrete claims in this respect. Whenever possible, there is a need for multicentered studies with large populations among homogenous groups.

The non-specific and non-infectious stimulation of PCT is far lower when compared with the other markers of inflammatory response. In local and systemic inflammation, successive monocytic activation is a prerequisite for PCT production (21-24). PCT serves as a chemo-attractant. Primarily, it is produced in coherent monocytes, but for more production, in the case of inflammation, it is produced by parenchymal cells in the inflammatory tissues. Peripheral blood mononuclear cells express PCT both on mRNA and protein levels. Lipopolysaccharides and various proinflammatory cytokines, such as IL-1 $\beta$, IL-2, IL- 6 and TNF-a, directly play an important role and indirectly have pronounced stimulatory effects on the expression of PCT mRNA (24-27). In our study, we found no significant association between PCT levels and the severity of ACS. Likewise, Sinning et al. (28) reported a significant difference in PCT between patients with AMI and USAP and patients with SAP, but no such difference between AMI and USAP.

In our study, we assessed the test group and control group in terms of HP, CMV, and CP antibodies, but found no difference between the two groups. Likewise, Padmavati et al. (29) compared a group of CAD patients with the control group in terms of HP, CMV, and $C P$ antibodies, and found no difference between the two groups. In a similar study, Mundkur et al. (30) found no difference between the CAD group and control group in terms of HP and CP antibodies, but a significant increase in CMV antibodies in the patient group. In a recent study, Nikitskaya et al. (31) showed that the amount of CMV viral DNA copies in the plasma of patients with ACS was higher than in healthy volunteers. Tabata et al. (32) found that HP-seropositivity and interleukin-1 polymorphisms were associated with higher levels of high-sensitivity C-reactive protein and elevated ST-segment elevation myocardial infarction risk.

When summarized, in the comparison of ACS patients with stable patients or healthy controls, there was a significant difference in terms of inflammatory markers, but no difference when AMI and USAP were compared. In the comparison of blood parameters determined after 48 hours, there was no apparent difference in the stable patients whereas there were important changes in the parameters of the ACS patients. Although the results of our study are compatible 
with some of the other studies, we think that the number of patients in our study groups, the characteristics of the patients; no distinct separation in AMI, USAP, SAP, and healthy controls or uniting the mentioned disorder groups to form heterogeneous groups for comparison; and regional differences caused difficulty in drawing definite conclusions from the results obtained.

\section{Study limitations}

This study included a limited number of patients. For this reason, the data obtained cannot be generalized. Also, since the test patients and control patients in the study were consecutive patients referring to our emergency department, there were differences between these two groups in terms of anamnesis and sex. How this situation affected the results is unknown.

\section{Conclusion}

The concept of inflammation in atherosclerosis has been increasingly accepted and the proven role of inflammation in atherogenesis has attracted a lot of interest from investigators. At present, it is clear that the inflammatory process plays a key role, not only at the beginning and progression of atherosclerosis, but also in the stabilization of the atherosclerotic plaque. Defining the cellular and molecular pathways of inflammatory cytokines in the formation of atherosclerosis has now become the main aim of studies for preventing atherosclerosis in cardiovascular diseases and developing strategies for its reversal. Although our knowledge of vascular biology and clinical results of atherosclerosis has increased much in the last few years, the roles of inflammatory cytokines and the load of infectious pathogens in determining the severity of coronary disease in acute coronary events have not been fully clarified due to different results obtained in various studies. An association could not be established between the severity of the coronary lesion and the cytokine levels because of the rise in inflammatory cytokine levels, independent of atherosclerosis in acute coronary events. On the other hand, in stable patients who were not in acute stress due to angina, an association between the cytokine level and severity of coronary lesion could not be determined. To determine the association between control cytokine levels and coronary risk, further investigations with control coronary angiography and assessment of cytokine levels performed over a long period of time after acute coronary syndrome are recommended.

Ethics Committee Approval: Ethics committee approval was received for this study from the Ethics Committee of Meram School of Medicine (24.02.2011, Decision No: 056).

Informed Consent: Written informed consent was obtained from patients who participated in this study.

Peer-review: Externally peer-reviewed.

Conflict of Interest: No conflict of interest was declared by the authors.

Financial Disclosure: This study was supported by Konya Training and Research Hospital Research Projects Support Fund.

\section{References}

1. Ross R. Atherosclerosis - an inflammatory disease. N Engl J Med 1999; 340: 115-26. [CrossRef]
2. Fuster V, Badimon L, Badimon JJ, Chesebro JH. The pathogenesis of coronary artery disease and acute coronary syndromes. N Engl J Med 1992; 326: 242-50. [CrossRef]

3. Kornowski R, Hong MK, Tio FO, Brambell O, Wu H, Leon MB. In-stent restenosis: contributions of inflammatory responses and arterial injury to neointimal hyperplasia. J Am Coll Cardiol 1998; 31: 224-30. [CrossRef]

4. Gotsman I, Stabholz A, Planer D, Pugatsch T, Lapidus L, Novikov Y, et al. Serum cytokine tumor necrosis factor-alpha and interleukin- 6 associated with the severity of coronary artery disease: indicators of an active inflammatory burden? Isr Med Assoc J 2008; 10: 494-8.

5. Potekhina AV, Sokolov VO, Pylaeva EA, Provatorov SI, Masenko VP, Bosykh $E G$ et al. Changes of content of regulatory lymphocytes and concentration of soluble interleukine-2 receptor in blood of patients with ischemiche heart disease after coronary artery angioplasty with implantation of stents with rapamyc covering. Kardiologiia 2011; 51:47-53.

6. Wang TJ, Nam BH, Wilson PW, Wolf PA, Levy D, Polak JF, et al. Association of $\mathrm{C}$-reactive protein with carotid atherosclerosis in men and women: the Framingham heart study. Arterioscler Thromb Vasc Biol 2002; 22: 1662-7. [CrossRef]

7. Ridker PM, Hennekenes $\mathrm{CH}$, Buring JE, Rifai N. C-reactive protein and other markers of inflammation in the prediction of cardiovascular disease in women. N Engl J Med 2000; 342: 836-43. [CrossRef]

8. Nicolle LE. Chlamydia pneumoniae and atherosclerosis: the end? Can J Infect Dis Med Microbiol 2005; 16: 267-8. [CrossRef]

9. Zibaeenezhad MJ, Amanat A, Alborzi A, Obudi A. Relation of Chlamydia pneumoniae infection to documented coronary artery disease in Shiraz, Southern Iran. Angiology 2005; 56: 43-8. [CrossRef]

10. Oshima T, Ozono R, Yano Y, Oishi Y, Teragawa H, Higashi Y, et al. Association of Helicobacter pylori infection with systemic inflammation and endothelial dysfunction in healthy male subjects. J Am Coll Cardiol 2005; 45: 1219-22. [CrossRef]

11. Zhu J, Quyyumi AA, Norman JE, Csako G, Waclawiw MA, Shearer GM, et al. Effects of total pathogen burden on coronary artery disease risk and C-reactive protein levels. Am J Cardiol 2000; 85: 140-6. [CrossRef]

12. Gensini GG. A more meaningful scoring system for determining the severity of coronary heart disease. Am J Cardiol 1983; 51: 606. [CrossRef]

13. Tedgui A, Mallat Z. Cytokines in atherosclerosis: pathogenic and regulatory pathways. Physiol Rev 2006; 86: 515-81. [CrossRef]

14. Ridker PM, Hennekens $\mathrm{CH}$, Buring JE, Rifai N. C-reactive protein and other markers of inflammation in the prediction of cardiovascular disease in women. N Engl J Med 2000; 342: 836-43. [CrossRef]

15. Hoffman M, Blum A, Baruch R, Kaplan E, Benjamin M. Leukocytes and coronary heart disease. Atherosclerosis 2004; 172: 1-6. [CrossRef]

16. Sukhija R, Fahdi I, Garza L, Fink L, Scott M, Aude W, et al. Inflammatory markers, angiographic severity of coronary artery disease, and patient outcome. Am J Cardiol 2007; 99: 879-84. [CrossRef]

17. Heinisch RH, Zanetti CR, Comin F, Fernandes JL, Ramires JA, Serrano CV $J$. Serial changes in plasma levels of cytokines in patients with coronary artery disease. Vasc Health Risk Manag 2005; 1: 245-50.

18. Sakamoto A, Ishizaka N, Saito K, Imai Y, Morita H, Koike K, et al. Serum levels of IgG4 and soluble interleukin-2 receptor in patients with coronary artery disease. Clin Chim Acta 2012; 413: 577-81. [CrossRef]

19. Nijm J, Wikby A, Tompa A, Olsson AG, Jonasson L. Circulating levels of proinflammatory cytokines and neutrophil-platelet aggregates in patients with coronary artery disease. Am J Cardiol 2005; 95: 452-6. [CrossRef]

20. Hu WS, Hwang JM. Association of Serum Cytokines, Human Growth Hormone, Insulin-Like Growth Factor (IGF)-I, IGF-II and IGF-Binding Protein (IGFBP)-3 with Coronary Artery Disease. Chin J Physiol 2012; 55: 267-73.

21. de Werra I, Jaccard C, Corradin SB, Chioléro R, Yersin B, Gallati H, et al. Cytokines, nitrite/nitrate, soluble tumor necrosis factor receptors, and procalcitonin concentrations: Comparisons in patients with septic shock, cardiogenic shock, and bacterial pneumonia. Crit Care Med 1997; 25: 607-13. [CrossRef] 
22. Meisner M, Adina H, Schmidt J. Correlation of procalcitonin and C-reactive protein to inflammation, complications, and outcome during the intensive care unit course of multiple-trauma patients. Crit Care 2006; 10: R1. [CrossRef]

23. Wanner GA, Keel M, Steckholzer U, Beier W, Stocker R, Ertel W. Relationship between procalcitonin plasma levels and severity of injury, sepsis, organ failure, and mortality in injured patients. Crit Care Med 2000; 28: 950-7. [CrossRef]

24. Erren M, Reinecke H, Junker R, Fobker M, Schulte H, Schurek JO, et al. Systemic inflammatory parameters in patients with atherosclerosis of the coronary and peripheral arteries. Arterioscler Thromb Vasc Biol 1999; 19 2355-63. [CrossRef]

25. Wunder C, Eichelbrönner O, Roewer N. Are IL-6, IL-10 and PCT plasma concentrations reliable for outcome prediction in severe sepsis? A comparison with APACHE III and SAPS II. Inflamm Res 2004; 53: 158-63. [CrossRef]

26. Oberhoffer M, Stonans I, Russwurm S, Stonane E, Vogelsang H, Junker U, et al. Procalcitonin expression in human peripheral blood mononuclear cells and its modulation by lipopolysaccharides and sepsis-related cytokines in vitro. J Lab Clin Med 1999; 134: 49-55 [CrossRef]
27. Reilly MP, Rohatgi A, McMahon K, Wolfe ML, Pinto SC, Rhodes T, et al. Plasma cytokines, metabolic syndrome, and atherosclerosis in humans. J Investig Med 2007; 55: 26-35. [CrossRef]

28. Sinning CR, Sinning JM, Schulz A, Schnabel RB, Lubos E, Wild PS, et al. Association of serum procalcitonin with cardiovascular prognosis in coronary artery disease. Circ J 2011; 75: 1184-91. [CrossRef]

29. Padmavati S, Gupta U, Agarwal HK. Chronic infections \& coronary artery disease with special reference to chalmydia pneumoniae. Indian J Med Res 2012; 135: 228-32.

30. Mundkur LA, Rao VS, Hebbagudi S, Shanker J, Shivanandan H, Nagaraj RK and et al. Pathogen burden, cytomegalovirus infection and inflammatory markers in the risk of premature coronary artery disease in individuals of Indian origin. Exp Clin Cardiol 2012; 17: 63-8.

31. Nikitskaya EA, Grivel JC, Maryukhnich EV, Lebedeva AM, Ivanova OI, Savvinova PP, et al. Cytomegalovirus in plasma of acute coronary syndrome patients. Acta Naturae 2016; 8: 102-7.

32. Tabata N, Sueta D, Akasaka T, Arima Y, Sakamoto K, Yamamoto E, et al. Helicobacter pylori seropositivity in patients with Interleukin-1 polymorphisms is significantly associated with ST-Segment Elevation Myocardial Infarction. PLoS One 2016; 11: e0166240. [CrossRef] 